\title{
LA CULTURA De la Violencia en Chile
}

\author{
Por: Jorge Vergara Estévez*
}

\section{Resumen}

Lo que podría llamarse una "cultura de la violencia" en Chile es una organización social y una forma de vida en las cuales la violencia es un recurso permanente, enraizado en las relaciones sociales y en las interacciones cotidianas. Primeramente se ofrecen algunos antecedentes históricos sobre la violencia social y política desde la Conquista hasta el golpe de 1973; lvego se caracterizan los rasgos principales de la represión política y del sistema represivo chileno. Finalmente, se muestran las principales expresiones que asume la violencia social y cotidiana, y se enuncia una hipótesis interpretativa sobre el incremento de estas formas de violencia durante el período autoritario.

\section{Palabras Claves}

Cultura de la violencia, represión política, totalitarismo, imaginario social, Estado oligárquico, coerción.

\section{THE CULTURE OF VIOLENCE IN CHILE}

\section{Abstract}

A "culture of violence" in Chile is a social fabric and a lifestyle in which violence becomes a recurring well established mean within social relations and day-to-day interactions.

In the first part, we consider the historical background on the social and political violence from the Conquest period through the 1973 military coup; then we describe the main features of the Chilean political repression system.

In the last section, we describe the predominant expressions taken

\section{*Perfil}

Jorge Vergara Estévez es Magíster y Candidato a Doctorado en Filosofía de la Universidad de Paris VIII. Profesor de la Universidad de Chile, investigador en filosofía y teoría polífica. Miembro de la comisión de Epistemología y Política en CLACSO on by social and workaday violence and elicit a hypothesis interpreting the dramatic increase of these forms of violence during the authoritarian political period.

\section{Key Words}

Culture of violence, political repression, totalitarianism, social imaginary, oligarchic State, coercion.

Artículo: Recibido, 28 de septiembre de 2007; aprobado, 28 de noviembre de 2007 
En nuestro imaginario social, los chilenos somos un pueblo "pacífico y civilizado" que, desgraciadamente, ha sufrido el accidente de una larga dictadura militar. A menudo esta representación es compartida por los extranjeros. Recientemente, decía David Turner, presidente de la compañía Shell en Chile: «La visión de futuro que mi compañía tiene de Chile es que se trata de un país $\sin$ conflictos internos serios. No hay problemas étnicos, religiosos ni limítrofes»'. Para nuestra mirada social, la violencia de la sociedad chilena consiste, básicamente, en la represión política. Deseamos creer que ella se minimizará o desaparecerá con la transición democrática que está comenzando. Queremos pensar que todos los conflictos y tensiones sociales podrán procesarse políticamente y disolverse por la vía del diálogo y la concertación. Por ello que, en nuestro medio, los discursos sólo se refieren a la violencia en su forma política directa, y nos hacen pensar que ella es episódica, rápidamente superable y que su mantenimiento sólo se debe a la acción de los adversarios políticos. Incluso en aquellos casos donde se llega a percibir parcialmente la diversidad de sus expresiones, suele atribuirse la violencia a una causa simple y abstracta, por ejemplo, la falta de caridad o la agresión del totalitarismo.

Este imaginario social se ha formado soslayando o ignorando tendencias relevantes de la historia nacional de Chile, la que, indudablemente, se ha desarrollado bajo el signo de la violencia desde sus ínicios. A diferencia de lo que sucedió en otras regiones de América, parte importante de los indígenas chilenos, los mapuches, que vivían en la zona sur, no aceptaron la dominación española. Dotados de notables cualidades militares y un profundo sentido de la libertad lograron contener la colonización española y mantuvieron un estado de guerra en todo el período colonial.Este conflicto que se dio en una sociedad estamental, basada en la hacienda y orientada a la exportación de materia prima, contribuyó de modo decisivo a determinar el perfil de la administración colonial en Chile y sus relaciones con la sociedad. Esta forma de administración se caracterizó por un marcado centralismo; alta cohesión del sector dominante español y criollo; fuerte presencia del ejército la mayoría de los gobernadores españoles fueron militares profesionales - y un acentuadoautoritarismo en su relación con la sociedad y, especialmente, con los sectores populares. A comienzos del siglo XVII, por ejemplo, el gobernador García Ramón, exasperado por sus fracasos militares en la guerra con los mapuches, ordenó "a todos los ministros de guerra que pasasen a cuchillo todo cuanto en ella se tomase, sin reservar mujer ni criatura, lo cual se puso en ejecución generalmente ${ }^{2}$. La Independencia, en nuestro caso, adquirió la forma de una cruenta guerra civil, que se prolongó por más de una década.

La vida social y política de la República hasta el golpe militar de 1973 no corresponde, tampoco, a nuestro imaginario social. Las relaciones con los mapuches constituyen una expresión de la presencia de la violencia en el período. En 1848 el gobierno chileno dejó de reconocer los títulos de dominio que los gobernadores españoles y la propia República habían entregado a los huilliches. Se inició, entonces, un proceso de usurpación de tierras indígenas por los colonos chilenos y luego alemanes, que fueron instalados en esos territorios al sur de Chile. Los indígenas trataron de resistir y el último gran levantamiento, en 1881, fue sofocado por el ejército. A consecuencia del mismo, su territorio se redujo al 5 por ciento. Otros pueblos indígenas, como los onas y los alacalufes, fueron exterminados por los estancieros chilenos, el alcohol y las enfermedades. Durante el siglo XIX, Chile sostuvo tres guerras, una con España y dos con Perú y Bolivia, además de varias guerras civiles. La mayor fue la de 1891, que dividió al pais en dos bandos que se enfrentaron en varias batallas, que dejaron miles de muertos. Valparaíso y luego Santiago, fueron saqueados por las tropas triunfantes, que obedecían al Congreso. La república parlamentaría que surgió de la derrota de Balmaceda vio surgir las primeras

1 Turner, David: Entrevisto en el diario El Mercurio, Sanfiago, 17/09/89.

2 Encina, Francisco Antonio: Resumen de la historia de Chile, tomo I, p. 172, Edit. Zig-Zag, Santiago,1954. 
organizaciones obreras de tendencias socialistas y anarquistas, especialmente en los enclaves salitreros del Norte. Se produjeron las primeras grandes huelgas. La respuesta del Estado oligárquico fue cruelmente represiva. Sólo en la Escuela de Santa María de lquique fueron asesinados por el ejército 2.500 trabajadores salitreros con sus familias. Durante el periodo del Estado de compromiso, que corresponde al de mayor desarrollo democrático, desde 1932 hasta 1973 , en casi todos los gobiernos hubo matanzas de obreros, pobladores, campesinos y estudiantes.

Recordemos un caso dramático de los últimos años del período democrático, que anuncia y prefigura la represión del régimen militar. En marzo de 1969, en Puerto Montt, un grupo de pobladores invadieron un terreno particular llamado Pampa Irigoin, buscando un sitio donde vivir. Al amanecer del 9 de marzo, tropas especiales de Carabineros (policía militarizada) asaltaron el improvisado campamento. "Despabilados por el estruendo, hombres y mujeres intentaron abandonar sus chozas, mientras los carabineros las desmantelaban a culatazos. Algunos ensayaron una débil defensa. Otros, los más, huyeron hacia una 'población' vecina. De nada les valió; los carabineros tenían rodeado el lugar $y$, ante una orden, procedieron a disparar tupidas ráfagas de metralletas y bombas lacrimógenas contra los pobladores. Luego rociaron las mejoras con bencina y les prendieron fuego. Alumbrados por las llamas, como condenados en el infierno, los pobladores corrían de un lado para otro, tratando de encontrar una salida al cerco fatal. Pero todo fue en vano: estaban sentenciados. Alli cayeron varios muertos. 'Oímos los disparos, él se levantó. Se estaba poniendo la ropa cuando le dio la bala. Eran como las siete y media, se desangró hasta la 9 ; no lo podíamos sacar; no ve que los carabineros estaban ahí. Irene Cárcamo Millán, cuenta, con frases entrecortadas, el asesinato de su esposo, Federico Contreras. Las nubes del humo y la semiclaridad de la aurora no permitían apreciar las verdaderas proporciones de la tragedian.
La coerción estatal no se ejercía, únicamente, contra los sectores populares que defendian sus reivindicaciones sociales. La experimentaban también delincuentes comunes quienes eran maltratados, con frecuencia sometidos a tortura y hacinados en cárceles inhumanas, en medio de la indiferencia de la sociedad. Tanto en estos casos, como en los de violencia social o política, los funcionarios estatales que la cometieron nunca fueron sancionados. La impunidad de estos funcionarios ha sido constante. En una visión de conjunto, puede decirse que en Chile la violencia ha provenido casi siempre del Estado y los sectores dominantes. La violencia de los subordinados ha sido esporádica y reactiva frente a situaciones de extrema opresión.

\section{Bajo el régimen militar}

El golpe de Estado de 1973 inauguró en Chile un período de extrema violencio. El bombardeo aéreo del Palacio de la Moneda fue un signo inequívoco del nuevo poder autoritario. Desde el comienzo ha carecido de límites políticos y éticos y se ha regido por el cálculo de la eficacia. Su proyecto era el de construir un nuevo orden social y político, fundado en el dominio de un bloque de poder conservador de carácter militar y civil, capaz de dirigir un proceso radical de modernización capitalista. Los sectores conservadores vivieron los conflictos sociales y políticos que se produjeron durante el gobierno del presidente Allende como una amenaza radical, no sólo a su estatus y poder social, sino, incluso, a su sobrevivencia personal. Percibieron la mantención de ese gobierno como un peligro catastrófico. Interpretaban su pérdida de hegemonía y poder como decadencia de la sociedad chilena y como disolución de sus valores fundamentales. La única solución radicaba en la recuperación de dichos valores y la restauración modernizante del orden social amenazado. Dicho orden fue idealizado y se le atribuyeron todos los valores: encarna a la plena libertad, la verdadera justicia, la prosperidad, la grandeza nacional, etcétera. Sus opositores fueron exorcizados, y declarados enemigos de la

3 Urrutia, Cecilia: Historia de las poblaciones callampos, pp 9 y 11, Quimantú, Santiago, 1972. 
civilización occidental, la propiedad, la moral, la familia, Dios y la Iglesia. Franz Neumann ha mostrado que la angustia que provocan los períodos de conflicto social puede transformarse en angustia persecutoria cuando un grupo social se siente amenazado, sin lograr comprender el proceso social que está viviendo. Dicho grupo puede asumir actitudes emocionales regresivas. La más importante es la de la teoría de la conspiración, que personifica el proceso histórico. «El odio, el resentimiento y el miedo que crean los grandes cataclismos se concentra en ciertas personas, a las cuales se denuncia como perversos conspiradores, como enemigos auténticos que es necesario extirpar ${ }^{4}$.

Estas representaciones fueron reforzadas y "confirmadas" por la evolución que venía experimentando el pensamiento político de los militares chilenos desde la década del 60. El cambio fundamental consistió en que la Doctrina de la Seguridad Nacional sustituyó las concepciones precedentes, según las cuales el papel fundamental de las Fuerzas Armadas era el de preservar la soberanía nacional y mantener su subordinación al poder político generado democráticamente. Con esta nueva concepciónse convertían en el centro de poder del Estado, las principales responsables subordinación al poder político generado democráticamente. Con esta nueva concepción se convertían en el centro de poder del Estado, las principales responsables de la "seguridad nacional» y las depositarias de los valores fundamental es de la identidad históricocultural de la patria. Todo este patrimonio se encuentra amenazado por la "agresión marxista». Vivimos una situación de guerra permanente, en la cual las Fuerzas Armadas y los verdaderos chilenos se enfrentan contra los agentes internos del enemigo internacional. "Todos sabemos que el mundo de hoy se divide políticamente en occidentales y orientales; es decir, demócratas y marxistas. La lucha entre ambos bandos, aunque lo hacen estratégicamente, sobre todo las grandes potencias, es a muerte», nos enseña la revista Armas y servicios del Ejército ${ }^{5}$. Los enemigos internos pueden asumir las más diversas e, incluso, inofensivas apariencias; infiltran todas las instituciones y organizaciones y prosiguen incansablemente su tarea de desquiciamiento y de preparación para la conquista del poder total. "No se puede negar que los comunistas tienen mística, se las da el Demonion, ha dicho el general Pinochet.

Esta "construcción social de realidad» puede ayudarnos a comprender el carácter estratégico, la magnitud y constancia del sistema represivo chileno. Después de una primera fase relativamente espontánea, la represión se convirtió en sistema organizacional que planifica y realiza las prácticas represivas, de acuerdo a un análisis permanente de la coyuntura política. Los distintos servicios de inteligencia y la policía cuentan con la colaboración permanente de diversos organismos estatales. Los tribunales casi nunca investigan y sancionan la violación permanente de los derechos humanos. Los medios de comunicación social - especialmente los canales de televisión, que son todos estatales - sólo difunden las versiones oficiales sobre los hechos represivos. El Instituto Médico Legal (la morgue) adecúa sus informes técnicos a las necesidades gubernativas. Las compañías de teléfono y de correo que son semiestatales intervienen las llamadas y la correspondencia. Las universidades, institutos y colegios públicos y municipales informan sobre sus profesores, funcionarios y alumnos a los servicios de seguridad. Las Juntas de Vecinos, designadas por los alcaldes, nominados por el gobierno cumplen similares funciones de delación política en cada barrio o lugar del territorio, etcétera. Este sistema cuenta además con la colaboración espontánea - solicitada de medios de comunicación y diversas empresas privadas, taxistas y otros.

El régimen militar ha dictado una amplia legislación y ha adaptado leyes precedentes para legalizar sus prácticas represivas. Ello cumple diversos objetivos: por una parte, proporciona a los aparatos represivos, las fuerzas armadas y sus

4 Neumann, Franz: «Angustia y política», en El Estado democrático y el Estado autoritario, p. 261, Ed. Paidós, Buenos Aires, 1968. 5 Ventura, Juan de la Rosa: "El 'Juego' de los derechos humanos", p. 21, Revista Armas y servicios del ejército, N 19, Santiago, 1980. 
partidarios, la confianza de que dichas acciones poseen amplia legalidad; por otra, han ampliado el fuero militar, de modo que los funcionarios de las instituciones armadas sólo pueden ser juzgados por tribunales militares, a menos que sean puestos por aquéllos a disposición de la justicia civil. Esos mismos tribunales militares han ampliado su competencia, de tal modo que casi todos los procesos políticos deben seguirse allí; finalmente, las modificaciones realizadas obstaculizan y bloquean la posibilidad de que los tribunales civiles lleguen a juzgar los delitos de violación de los derechos humanos. Esta legislación no sólo corresponde a la tradición legalista de la cultura chilena, sino que expresa la voluntad política de constituir un Estado autoritario que permanezca en el tiempo.

\section{Racionalidad y años de toque de queda}

Otro rasgo estructural del sistema represivo chileno es su desproporción con las acciones de la oposición social y política, y su carácter permanente. Durante la mayor parte de estos años, el régimen militar gobernó con estados de excepción y toque de queda. Ha detenido a cientos de miles de sus opositores, ha maltratado y torturado a decenas de miles de detenidos, ha perpetrado miles de ejecuciones extrajudiciales; ha detenido y hecho desaparecer a más de mil chilenos; hasta 1988 tuvo exiliados a cientos de miles de personas; mantuvo en campos de concentración o prisiones a miles de presos políticos. Ha usado el amedrentamiento a través de todas sus formas: la pérdida de nacionalidad, la relegación, ha despedido o hecho despedir de su trabajo a cientos de miles de opositores, etc. En casi todos estos casos, esta violencia se ejerció sobre personas desarmadas, que no oponían resistencia $y$, muchas veces, incluso sobre niños. Desde 1973, no ha existido un movimiento de lucha armada capaz de amenazar efectivamente al gobierno. Nunca hubo una "guerra», es decir, un conflicto entre dos o más bandos armados, donde el mando civil podría vencer al estatal, o al menos presentar una resistencia efectiva a su poder militar.

Al no existir proporción entre el nivel y las características de la represión y la real amenaza a la estabilidad del régimen, podemos sostener que su función principal es estratégica y preventiva. Lo que caracteriza a este régimen militar, a diferencia de otros que se dieron en América Latina, es la coherencia de su proyecto fundacional, es decir, el intento - relativamente frustrado después del plesbicito de 1988 - de creación de un nuevo sistema de dominación de capitalismo autoritario. La represión fue una condición necesaria de la aplicación de su modelo económico, político, jurídico, ideológico y organizacional. Ella ha operado como gigantesco dispositivo de disciplinamiento de la sociedad y adaptación al orden autoritario. Se ha ejercido sobre una población debilitada por el empobrecimiento, el deterioro e inestabilidad de su situación laboral. Su función sigue siendo preventiva. Se tortura a los militantes políticos que podrían convertirse en dirigentes importantes. El asesinato político fue usado para eliminar figuras políticas que pudieran haber llegado a unificar importantes sectores de la oposición. Se hizo desaparecer o se castiga duramente a miembros de base de organizaciones políticas y sociales, no por su "peligrosidad» individual, sino como un modo de agredir a las organizaciones sociales a las cuales pertenecen. Se trata de atemorizar, y aumentar el sentimiento de vulnerabilidad del grupo y de la oposición en conjunto. A diferencia de la estrategia nazi, que buscaba disolver los grupos tradicionales para reconstruir la sociedad en base a nuevos grupos; el autoritarismo chileno consiguió durante una década, aproximadamente, fragmentar y atomizar la sociedad, destruyendo o debilitando los grupos y organizaciones tradicionales de los sectores subordinados.

La eficacia política que alcanzó el sistema represivo chileno no hubiera sido posible sin el alto grado de burocratización y tecnificación que pudo alcanzar a los pocos años de su creación. Ella fue producto de una cuidadosa planificación, elaborada por equipos de especialistas militares y civiles, que incluian sociólogos, psicólogos, expertos en medios de comunicación, médicos, entre otros. Los aparatos represivos chilenos poseen centros de entrenamiento, laboratorios diversos, clínicas, estudios de video, imprentas que editan revistas de circulación pública, una central de procesamiento de datos y computación que ocupa un edificio entero en el centro de Santiago 
decenas de lugares clandestinos de detención y tortura, sofisticados instrumentos de espionaje («orejas" electrónicas, interceptores diversos, etc.), enormes medios económicos y amplias planillas de agentes y colaboradores. Se dice que sólo la inversión inicial para crear la DINA, que hoy se llama Central Nacional de Informaciones (CNI), alcanzó a 40 millones de dólares. Informaciones periodísticas afirman que sólo este organismo emplea a 13.000 personas.

Existe un alto grado de estandarización de las técnicas represivas Por ejemplo, Amnistía Internacional en su informe especial sobre tortura en Chile, de 1983, muestra que en todos los casos ésta fue realizada por el CNI en el mismo centro clandestino, utilizando el mismo ritual y los mismos procedimientos ${ }^{6}$. La burocratización se expresa también en la división del trabajo en los aparatos represivos. Existirian departamentos especializados en cada uno de los partidos politicos importantes, las iglesias, especialmente la católica, los sindicatos. El espionaje de los exiliados ocupaba divisiones especiales. Existe una oficina de intercepción del servicio postal que funciona en la Dirección General del Correo y, probablemente, oficinas especiales para la intercepción telefónica. Todo indica que hay grupos especiales destinados a la ejecución de prisioneros políticos. Todo esto permitió decir al general Pinochet: «no se mueve una hoja en el país, sin que yo lo permita». Esta división del trabajo diluye las responsabilidades. Cada uno hace su parte y nadie se siente responsable por el resultado final. Asimismo, otorga a los funcionarios de seguridad la ilusoria identidad de "profesionales" que miden la racionalidad de su trabajo exclusivamente por su eficacia.

El sistema represivo chileno posee un alto nivel tecnológico, es decir, sus procedimientos y operatoria incorporan y se guían por conocimientos científicos provenientes de la medicina, la psicología, la sociología, la ciencia política, etcétera. La mayor parte de las características de la detención, tratamientos en los centros de detención y cárceles, incluyendo las torturas, se fundan en conocimientos psicológicos actualizados. Podemos mencionar las técnicas de condicionamiento y descondicionamiento, basadas en la reflexología, la psicología de la percepción, los estudios de Milgram de obediencia a la autoridad, el psicoanálisis, etcétera. El encapuchamiento y otras técnicas de privación sensorial, el aislamiento las humillaciones, especialmente las de tipo sexual, la desnudez, la alteración del sueño, etcétera, buscan aniquilar psicológicamente al individuo, convertirlo en un delator de sus compañeros, quebrar su autoimagen destruyendo su identidad personal. Veamos algunos testimonios. Habla una niña de 12 años, cuyo padre fue torturado: "Cuando mi papá volvió a la casa estaba cambiado... parecía que no nos escuchaba... todo le molestaba. Mi mamá le preguntaba que qué le habían hecho y él decía que nada. En las noches a veces, despertaba gritando como si lo estuvieran matando y después lo sentíamos llorar bajito un rato. A mí me hubiera gustado poder consolarlo, pero no me atrevian?

\section{La violencia social y cotidiana}

La presencia inocultable de la violencia política, que ha provenido casi enteramente de los aparatos gubernativos, nos ha impedido a los chilenos darnos cuenta de la creciente violencia social y cotidiana que no es directamente política. La mirada social es como un haz de luz que, al mismo tiempo que ilumina, destaca y patentiza una parte de la realidad, minimiza, oculta u oscurece otros aspectos de ella. El conjunto de la realidad social siempre rehuye nuestra mirada.

La violencia policial no es nueva en nuestro pais, y siempre ha estado ligada a la represión política. Durante el período democrático la policía usaba excesiva violencia para reprimir manifestaciones, "tomas" de sitios, huelgas y otras acciones consideradas ilegales. En los sucesos de Pampa Irigoin que mostrábamos al comienzo, actuó la policía de Carabineros. En la

6 Amnistía Internacional: La tortura en Chile, Ed. Fundamentos, Madrid, 1983.

7Colectivo de Salud Mental, informe, p. 19, mimeo, Santiago de Chile, 1986. 
investigación de delitos y el tratamiento de delincuentes habituales, la tortura a través de golpes y electricidad era una práctica habitual. Con el régimen militar, la violencia policial se acrecentó y se masificó. Durante estos años se han producido allanamientos y detenciones masivas. El 14 de mayo de 1983, por ejemplo, un "operativo" cubrió cuatro poblaciones y afectó a 5.000 hogares. «Todos los hombres mayores de 14 años, unas 10.000 personas, son sacadas a viva fuerza y en forma humillante y vejatoria de sus casas para chequear sus antecedentes. Unos 50 son apaleados, un número no determinado es apremiado con picanas eléctricas en el mismo lugar y 306 son retenidos y llevados a los recintos policiales. Una pobladora decía en su testimonio: 'Ellos se meten en nuestras casas. Nos golpean y destruyen todo. Además nos tienen sometidos a una guerra psicológica. Aunque todo esté tranquilo, día y noche ronda un helicóptero sobre nuestras cabezas' ${ }^{8}$. Dichas acciones carecen de efectividad para controlar la delincuencia, más aún, la acrecientan, al desactivar las organizaciones de base que limitan la acción de los delincuentes. Su evidente objetivo es amedrentar a los sectores populares y disminuir su oposición al régimen militar. Con frecuencia se realizan "redadas» especialmente en la noche, donde se detienen a muchos jóvenes por su apariencia o por el sólo hecho de estar en ciertos lugares. Muchos de los jóvenes detenidos son maltratados e, incluso, son torturados con golpes eléctricos. Asimismo, suelen producirse muertes en los recintos policiales, sea de delincuentes o detenidos por sospechas. Más aún, en los últimos años ha habido casos de peatones agredidos o muertos por policías embriagados, además de asaltos o robos a mano armada perpetrados por miembros de la policía o de los servicios de seguridad. La delincuencia, en especial el robo en sus diferentes modalidades, es una práctica frecuente en Chile. Las condiciones económicas y sociales del período autoritario han hipertrofiado el fenómeno. Para ello, basta considerar que la tasa de cesantía real durante estos años ha sido de, aproximadamente, un 15\% promedio En los jóvenes de sectores populares, a fines de 1985, alcanzaba al $48 \%{ }^{2}$. Sólo cuatro comunas populares de Santiago producen el $52 \%$ de los delincuentes registrados ${ }^{\text {TO }}$. Sus niveles educacionales y situación laboral son característicos de estos sectores. En 1985, el $62 \%$ de los detenidos procesados tenia sólo nivel educacional básico, el $39,6 \%$ no tenía oficio y un $22,3 \%$ era obrero. El Anuario de Estadísticas Policiales del mismo año consigna que entre 1975 y 1985 se ha producido un crecimiento de $75 \%$ de los casos entregados a la policía civil"'. Desde 1981 a 1985 la población de reclusos creció en $50 \%$ y el índice de criminalidad ha aumentado en $6,5 \%$ anual, es decir, casi el triple del crecimiento poblacional, que es de $2,2 \%$. Esto convierte a Chile en uno de los países de mayor nivel de delincuencia en América Latina, junto Colombia. El delito más común es el robo, que llega a $34 \%$. Este se define legalmente como apropiación de objetos por la violencia, intimidación de personas o fuerza sobre las $\operatorname{cosas}^{12}$. Escuchemos el testimonio de un delincuente de 18 años: «Yo me metí en la volá esa del robo porque no tenía nada que hacer. Trabajé un tiempo en el PEM (Programa de Empleo Mínimo del Estado), pero me echaron. Entonces me miraba y veía que no tenía plata, ni ropa que ponerme. Me empecé a juntar con los amigos del barrio, ahí aprendi a 'cogotear'. Les salía al paso de noche, con una cuchilla, y les decía que me pasaran la billetera, la chaqueta o las zapatillas» ${ }^{13}$.

Hay otro tipo de violencia, que no es directamente política, cuyos protagonistas no son especialmente competentes en su uso, como sucede con los policías y gran parte de los delincuentes. Esta violencia cotidiana surge en la calle, en las interacciones entre los automovilistas, en los conductores o choferes de la locomoción colectiva hacia los peatones y los

\footnotetext{
8 Revista Análisis: «Memorial de la dictadura 1973-1987», pp. 50 y 65, Santiago, 07/09/87.

9 Revista Apsi: «La esperanza acorralada», p. 26 (encuesta en 28 poblaciones de Santiago), Santiago,22/06/87.

10 Revista Apsi: «Delincuencia en Chile. Las razones de un incremento», p. 23, Santiago, 11/08/86.

11 Revista Apsi: “Delincuencia. Entre cuenteros, loros, giles y lanzas», p. 22, Santiago, 19/10/87.

12 Revista Apsi: idem (11), p. 22.

13 Revista Apsi: idem (12), p. 23.
} 
pasajeros, en los bares, en el hogar con la esposa e hijos, en las fiestas, hacia las mujeres y los niños; en suma, en cualquier lugar y situación. En la mayoría de los casos es ocasional, desproporcionada o injustificada. Ella está condicionada por los altos niveles de tensión y frustración que se vive, particularmente en Santiago.

La violencia intrafamiliar ha crecido notablemente en estos años, en especial los casos de niños o mujeres golpeados. Se ha dicho que no existe aumento real, sino sólo mayor caso de denuncias. Esta explicación es insuficiente, y los especialistas concuerdan en que existe un aumento neto de los casos. A tal punto ha aumentado la cifra de niños gravemente golpeados por sus padres y familiares que se ha creado una Corporación privada destinada a sensibilizar y educar a la opinión pública. Actualmente, la mayor causal de ingreso al Hospital Psiquiátrico de Santiago no es la depresión aguda, como en el pasado, sino la violencia intrafamiliar. Dice la esposa de un chofer de la locomoción colectiva: "Llegó a la casa todo hediondo y embarrado. Yo tiritaba porque siempre que llega borracho me ponía nerviosa. Yo no recuerdo lo que pasó después, pero esa vez me pegó y me insulto a míy alos niños»" ${ }^{14}$.

Chile tiene uno de los niveles más altos de América Latina en accidentes de tránsito y atropellos. La mayor parte de ello se debe a fallas humanas, debidas a la ebriedad de conductores y peatones. Se trata habitualmente de negligencia culpable, es decir, acciones donde no hubo el propósito consciente de perjudicar a otros, pero, sin embargo, se procedió de tal modo que era previsible un resultado semejante. Asimismo, es frecuente que los conductores actúen en forma prepotente o descuidada.

Un fenómeno nuevo, que apenas existía anteriormente, es el de la violencia de bandas juveniles, sea en sectores populares o de mayor ingreso. Se producen enfrentamientos a pedradas en los grupos de sectores populares $y$, frecuentemente, peleas entre distintas bandas, que ya han producido muertes. Es habitual que estas bandas ataquen a comerciantes, transeúntes, vecinos u otros jóvenes. Un diario informa recientemente: «Dos pandillas con una veintena de delincuentes motorizados mantuvieron atemorizados durante tres horas, en la madrugada de ayer, a vecinos del barrio Bellavista de Santiago. Con palos y piedras se atacaron mutuamente, destrozando vidrios de numerosas residencias y causando la interrupción de los servicios telefónicos y de electricidad $»^{15}$.

\section{Autoagresión, drogas, etc...}

Existen otras formas de violencia cotidiana donde no hay separación entre el agresor y el agredido: constituyen la misma persona. Se trata de los casos de autoagresión. En esta categoría encontramos los intentos de suicidio, fallidos o no, el alcoholismo, las diversas formas de drogadicción y otras conductas semejantes. El sentido común identifica la violencia con sus modalidades de acción sobre otro. Sin embargo, la psicología, especialmente el psicoanálisis, ha mostrado que no hay diferencia esencial entre la violencia dirigida a otro o a sí mismo. La observación muestra la presencia simultánea de conductas violentas hacia los otros y hacia sí mismo, particularmente en el caso de los alcohólicos. En nuestra opinión, estas dos grandes formas de violencia expresan y constituyen los dos rostros de la cultura de la violencia en Chile.

Antes del período autoritario, el consumo de drogas estaba limitado a ciertos círculos profesionales y a jóvenes intelectuales. En estas dos décadas se ha masificado, hasta convertirse en una catástrofe nacional. Estimaciones recientes de especialistas señalan que en los sectores juveniles poblacionales la drogadicción alcanza al 70\%, cubriendo una gama de solventes, fármacos, marihuana, etcétera. Una

14 Revista ¿Qué hacemos?: «Siempre se levantaba enojado»,p. 13, N²3, enero-febrero, s/a, Santiago.

15 Diario La Epoca: «Pandillas se apoderan de las calles del barrio Bellavista», p. 12, Santiago, 18/09/89. 
encuesta de la Vicaría Pastoral Juvenil de 1985 ya daba una cifra de 300.000 jóvenes que fumaban marihuana, es decir, más de la cuarta parte de la población juvenil de Santiago ${ }^{16}$. Como señala un médico: "En Chile, la droga más pesada se llama alcohol. Y la marihuana, aquí, es el prólogo del alcoholismon ${ }^{17}$. Los jóvenes chilenos, carentes de canales de participación, presionados por sus problemas familiares y económicos, tensionados por la incertidumbre de su futuro, limitados por el autoritarismo del ambiente social, encuentran en la marihuana un signo de identidad, de proximidad y complicidad con sus iguales. "Ahora se fuma mucha marihuana porque ésta se ha convertido en una especie de estandarte rebelde", señala un estudiante universitario, consumidor habitual $^{18}$.

Chile siempre tuvo una alta tasa de alcoholismo. Ello se debe no sólo a ciertas tradiciones culturales y características de la psicología nacional, sino también al hecho de que el alcohol ha sido siempre un mecanismo de control social, cuyo consumo es estimulado a través de la publicidad permanente y su venta indiscriminada. Dice un especialista: «El alcohol y el tabaco representan un negocio para muchos: los productores, las municipalidades, los gobiernos que obtienen impuestos. Detrás de ellos hay grandes intereses en juego" ${ }^{19}$. Durante este período hay un gran aumento de bebedores habituales y alcohólicos. No se han realizado estudios globales a nivel nacional, pero las estimaciones alcanzan al $20 \%$ de la población. Ha cambiado, asimismo, el perfil del bebedor. Se ha masificado en los jóvenes y se ha extendido a las mujeres y los niños. Una encuesta de la Vicaría Pastoral Juvenil revela que el $85 \%$ de los jóvenes dijo ingerir alcohol con cierta periodicidad ${ }^{20}$. Chile tenia una bajo tasa de alcoholismo femenino, que ha ido creciendo. Anteriormente los casos de alcoholismo en los niños se producian por inducción familiar; hoy encontramos casos de alcoholismo voluntario en menores de 14 años.

Las cifras reales de suicidio no han sido difundidas por los organismos gubernativos. Sin embargo, psiquiatras y terapeutas concuerdan en que Chile vive una gravisima crisis de salud mental que se expresa en el crecimiento exponencial de consultas psicológicas y de enfermedades psicosomáticas. La mitad de las consultas de policlínicos en sectores populares corresponde a problemas de esta naturaleza. El $49 \%$ de las personas de nivel socioeconómico alto y el $80 \%$ de las de los niveles más bajos presentan elevados niveles de angustia ${ }^{21}$. Encontramos elevadas frecuencias de neurosis y enfermedades psicosomáticas, atribuibles en forma casi exclusiva a las condiciones de trabajo ${ }^{22}$. En estas condiciones, no puede resultar sorprendente el elevado consumo de psicofármacos, en la mayoría de los casos por automedicación. Varios sedantes, por indicación del Ministerio de Salud, se venden libremente, sin necesidad de recetas.

Volviendo a los intentos de suicidio, en muchos casos éstos se deben a depresiones reactivas frente a situaciones de cesantía y de graves problemas económicos. Periódicamente los diarios informan de suicidios de ancianos que deben sobrellevar su soledad y enfermedades con jubilaciones ínfimas, que muchas veces no alcanzan al equivalente a 20 dólares mensuales. En general, las estadísticas muestran que los chilenos pobres son más propensos al suicidio que los de mayor ingreso. Se han producido cierta cantidad de casos entre las víctimas de la represión política: exiliados, ex-presos políticos, ex-detenidos y torturados, familiares de detenidos-desaparecidos, etc.

16 Revista Apsi: iLa yerba brujan, p. 29, Santiago, 27.06.87.

17 Idem, p. 31.

181 dem, p. 30.

19 Idem, p. 31

20 Revista Apsi, dem (10), pág. 27

21 Medina, F.: Características de los problemas de salud y de atención médica en los diversos subsectores de salud del Gran Santiago, 1983, CPU, Santiago, 1984

22 Duahart S, Infante A., Weinstein J.: Condiciones de trabajo y de salud ocupacional de los trabajadores de la flota pesquera de 


\section{Crisis de sociabilidad y subjetividad}

¿Por qué se ha producido en Chile este aumento cualitativo de la violencia social, cotidiana y autodestructiva en este período? Nuestra hipótesis es que ello se relaciona directamente con las transformaciones sociales, políticas y económicas durante el régimen militar.

Puede decirse, en general, que en nuestra sociedad las relaciones sociales son de tipo tradicional. El complejo sistema político que se desarrolló durante el Estado de compromiso hasta 1973, permitió el desarrollo del espacio público, la modernización creciente de las relaciones sociales y, en sus últimas décadas, la participación social y política de los sectores populares. Todo esto permitió atenuar y controlar la violencia propia de un sistema de relaciones sociales tradicionales, que tenía en la hacienda su modelo. El advenimiento de la dictadura significó la destrucción del sistema político democrático existente y la casi desaparición del espacio público, con la prohibición de los partidos políticos, el control de los medios de comunicación social, del sistema cultural y la casi extinción del tejido de organizaciones sociales, especialmente de los sectores populares. Todo esto significó la privatización de las relaciones sociales, la atomización y la fragmentación social, y el predominio de un marcado particularismo en dichas relaciones.

El nuevo Estado se convirtió en un reeducador autoritario de toda la sociedad. Las relaciones de simple dominación, sin mediaciones, que estableció con la sociedad civil, fueron el modelo para todas las relaciones sociales, organizacionales $e$, incluso, personales. Su lógica de concentración de poder y de imposición de las decisiones se ha extendido a toda la sociedad. Simultáneamente, la aplicación de las estrategias represivas, económicas y comunicacionales del régimen han significado una profunda alteración de la subjetividad de los chilenos. Esta se manifiesta en la desconfianza del otro la ansiedad por la constante incertidumbre y la autorrepresión de todas aquellas conductas y actitudes que pudieran ser consideradas "conflictivas" por el aparato policial o la disciplina de las organizaciones laborales, educacionales, entre otras.
La ausencia de un sentido común compartido; la carencia de la condición de ciudadano - recientemente recuperada - es decir, sujetos de desechos frente al Estado y al poder de la sociedad civil; el no ser reconocido como personas respetables y respetadas por el sólo hecho de ser chilenos; la carencia de un horizonte social de posibilidades y mínimas certidumbres para construir un proyecto de vida; la sumisión incondicional a que nos obligan las instituciones laborales y estatales, todo esto crea las condiciones en que la violencia social, cotidiana y autodestructiva, se desarrolla, se rutiniza y se profundiza.

Nuestro supuesto teórico es que tanto la política como el espacio público suministran un ámbito donde los individuos pueden reconocerse, procesar sus conflictos y desacuerdos, construir un mundo en común. Esto es condición de todo posible entendimiento y concertación democrática, por una parte. Por otra, también es necesario para generar resistencias y formas alternativas contra el particularismo y la violencia que emergen cotidianamente de las relaciones sociales. En una sociedad como la chilena, éstas no pueden sino ser conflictivas. Por ello podemos sostener que el periodo de transición democrática - que la sociedad chilena ha conseguido abrir con mucho sacrificio - constituye la condición y la posibilidad de intervenir en la cultura de la violencia en Chile. Sólo una sociedad capaz de conocerse a si misma, de reconocer sus miserias y limitaciones, puede llegar a transformarse y humanizarse. Sólo entonces podrá disminuir y controlar las diversas formas de violencia que emergen desde su interior. 


\section{Bibliografía}

Amnistia Internacional, LA TORTURA EN CHILE. Madrid, Ed. Fundamentos. 1983; Delincuencia. Entre cuenteros, loros, giles y lanzas.

Anónimo, ¿QUE HACEMOS?. 23. p13. Santiago; El sistema represivo del régimen militar chileno.

Anónimo, ANALISIS. p50, 65 - Santiago. 1987; Pandillas se apoderan de las calles del barrio Bellavista.

Anónimo, APSI. p22-23 - Santiago. 1987; Violencia.

Anónimo, APSI. p22, 27 - Santiago, 1986; Condiciones de trabajo y de salud ocupacional de los trabajadores de la flota pesquera de Arica e lquique.

Anónimo, APSI. p26 - Santiago. 1987; La yerba bruja.

Anónimo, APSI.p29-31 - Santiago. 1987;

Anónimo, LA EPOCA-PRENSA. 18/09. p12. Santiago. 1989; La cultura del miedo en la sociedad civil: reflexiones y propuestas.

Arendt. Hannah, SOBRE LA VIOLENCIA. México, Cuadernos de Joaquin Moniz. 1970;

Colectivo de Salud Mental, INFORME. p19. Santiago de Chile, Chile. 1986; Siempre se levantaba enojado.

Corradi, Juan, CRISIS Y TRANSFORMACION DE LOS REGIMENES AUTORITARIOS. Buenos Aires, Ed. Eudeba. 1985.

Duahart-S., Infante A.; Weinstein-J., PROGRAMA DE ECONOMIA DEL TRABAJO. - Santiago de Chile, Chile, Acaemia de Humanismo Cristiano. 1987;

Encina, Francisco-A., RESUMEN DE LA HISTORIA DE CHILE. I. p172 - Santiago, Edit. Zig-Zag. 1954; Cheresky, Isidoro; Chonchol, Jacques -- El 'Juego' de los derechos humanos.

Häsler, Alfred; Mitscherlich, Alexander; Bloch,
Ernest; Marcusej, Herbert; Fischer, Ernest, EL ODIO EN EL MUNDO ACTUAL. - Madrid, Alianza Editorial. 1973;

Medina, F., CARACTERISTICAS DE LOS PROBLEMAS DE SALUD Y DE ATENCION MEDICA EN LOS DIVERSOS SUBSECTORES DE SALUD DEL GRAN SATIAGO, 1983. - Santiago, CPU. 1984;

Neumann, Franz, EL ESTADO DEMOCRATICOY ELESTADO AUTORITARIO. p261 - Buenos

Aires, Argentina, Ed. Paidos. 1968; La esperanza acorralada.

Stoppino, Mario, DICCIONARIO DE POLITICA. - México, Siglo XXI Editores. 1982;

Turner, David, EL MERCURIO-PRENSA. 17/09. Santiago. 1989; Bobbio, Norberto; Matteuci, Incola --angustia y política.

Urrutia, Cecilia, HISTORIA DE LAS POBLACIONES CALLAMPAS. p9, 11 - Santiago, Quimantú. 1972; Memorial de la dictadura 1973-1987.

Ventura, Juan de la Rosa, ARMAS Y SERVICIOS DEL EJERCITO. 19 - Santiago. 1980; Delincuencia en Chile. Las razones de un incremento.

Vergara, Jorge, PONENCIA AL SEMINARIO INTERAMERICANO "LA GUERRA Y LOS NIÑOS" - Bogotá, Seminario interamericano La guerra y los niños. 1986;

Este artículo es copia fiel del publicado en la revista Nueva Sociedad N ${ }^{\circ} 105$ Enero- Febrero de 1990, ISSN: 0251-3552, <www.nuso.org>. 